Braz J Med Biol Res, January 2012, Volume 45(1) 8-12

doi: 10.1590/S0100-879X2011007500151

\section{Protective effect of the APOE-e3 allele in Alzheimer's disease}

B.V.P. de-Almada, L.D. de-Almeida, D. Camporez, M.V.D. de-Moraes, R.L. Morelato, A.M.S. Perrone, L. Belcavello, I.D. Louro and F. de-Paula

The Brazilian Journal of Medical and Biological Research is partially financed by

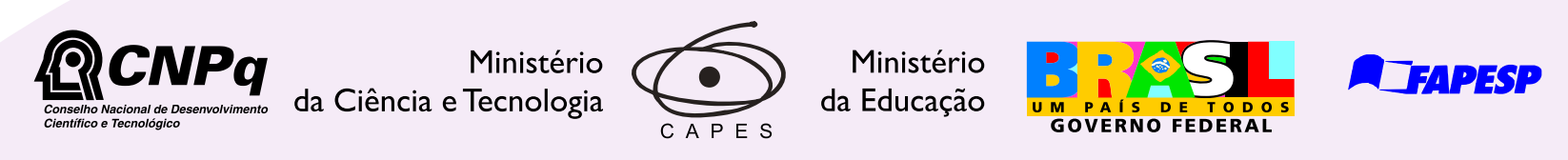

Institutional Sponsors
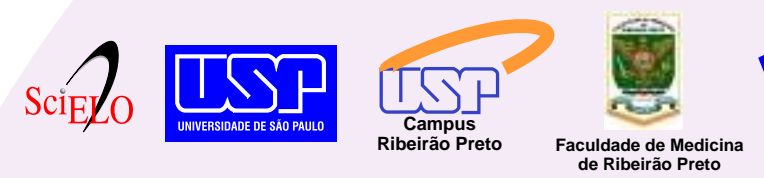

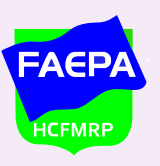

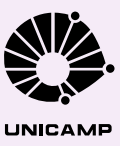

Ф SHIMADZu

A.

Associaçăo
Fundo de Incentivo
à Pesquisa

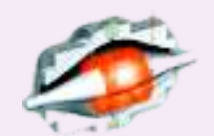

UNICAMP

lore High - Performance MS Orbitrap Technology analitica Thermo 


\title{
Protective effect of the APOE-e3 allele in Alzheimer's disease
}

\author{
B.V.P. de-Almada1 ${ }^{1}$, L.D. de-Almeida1 ${ }^{1}$, D. Camporez¹, M.V.D. de-Moraes ${ }^{1}$, \\ R.L. Morelato ${ }^{2}$, A.M.S. Perrone ${ }^{1}$, L. Belcavello ${ }^{1}$, I.D. Louro ${ }^{1}$ and F. de-Paula ${ }^{1}$ \\ ${ }^{1}$ Departamento de Ciências Biológicas, Universidade Federal do Espírito Santo, Vitória, ES, Brasil \\ ${ }^{2}$ Hospital da Santa Casa de Misericórdia de Vitória, \\ Escola Superior de Ciências da Santa Casa de Misericórdia de Vitória, Vitória, ES, Brasil
}

\begin{abstract}
Although several alleles of susceptibility to Alzheimer's disease (AD) have been studied in the last decades, few polymorphisms have been considered as risk factors for the disease. Among them, the APOE-e4 allele appears to be the major genetic risk factor for the onset of the disease. However, it is important to confirm the potential susceptibility of these genetic variants in different populations in order to establish a genetic profile for the disease in specific communities. This study analyzed the APOE polymorphisms regarding susceptibility to AD in a sample of 264 individuals (primarily Caucasians; 82 cases and 182 controls) in the population from Vitória, ES, Brazil, by PCR restriction fragment length polymorphism (PCR-RFLP) methods. The patients were selected according to clinical criteria for probable AD. Whereas the e4 allele showed statistically significant positive association with susceptibility to $\mathrm{AD}(\mathrm{OR}=3.01,95 \% \mathrm{Cl}=1.96-4.61 ; \mathrm{P}<0.0001)$, the $\mathrm{e} 2$ allele did not. The results of the e4 allele confirm the role of this polymorphism as a risk factor for $A D$ in the sample studied as observed in other populations. Although the $e 3$ allele has been considered neutral in several studies, our results suggest that it acts as a protective factor against AD in the population studied $(\mathrm{OR}=0.46,95 \% \mathrm{Cl}=0.30-0.67 ; \mathrm{P}<0.0001)$. This study may provide a new insight into the role of the $A P O E-e 3$ allele in the etiology of $A D$ and might help to estabilish a profile of risk for $A D$ in the population from Vitória, ES.
\end{abstract}

Key words: Alzheimer's disease; APOE-e3 allele; APOE-e4 allele; Brazilian population; Case-control study

\section{Introduction}

Alzheimer's disease $(A D)$ is a neurodegenerative disorder characterized by progressive deficit of cognitive function, with greater emphasis on memory loss and interference with occupational and social activities (1). Sporadic and late-onset AD (LOAD) shows a multifactorial heredity pattern caused by genetic and complex environmental interactions associated with several predisposing factors and age. The rate of cognitive deterioration during the development of $A D$ varies among individuals $(2,3)$ and seems to be guided by a combination of genetic and environmental factors (4). Some genes, such as CLU, PICALM, and CR1, have been shown to be related to $A D$ as indicated by genome-wide association studies (GWAS) $(5,6)$. However, only apolipoprotein $\mathrm{E}(A P O E)$ polymorphisms have been established as consistent genetic susceptibility factors for LOAD in all populations studied in the world (7).

In humans, the APOE gene is found in the $19 q 13.2$ region and presents three alleles (e2, e3, and e4). Stud- ies of association throughout the world have shown that the e4 allele acts as a strong dose-dependent risk factor for LOAD (8-10). Individuals with two copies of this allele are at a higher risk than those with only one copy (11). The $e 2$ allele seems to represent a protective factor both for familial $A D$ and for $L O A D$, although this protection is not observed in every population $(12,13)$. The e3 allele, considered neutral, is the most frequent in all populations studied $(10,14)$. Due to their clinical significance, it is very important to know the distribution of the alleles of the $A P O E$ gene in different populations in order to determine whether the polymorphisms of this gene has a universal effect on the risk for the development of AD.

Previous studies carried out on samples from Southeast [São Paulo, SP (15-18) and São José do Rio Preto, SP (19)], Northeast [Recife, PE $(15,16)$ ] and South [Porto Alegre, RS $(20,21)]$ of Brazil investigated the polymorphisms of the $A P O E$ gene, demonstrating a positive association of the $e 4$

Correspondence: F. de-Paula, Laboratório de Genética Humana e Molecular, Departamento de Ciências Biológicas/CCHN, UFES, Av. Mal. Campos, 1468, 29043-900 Maruípe, Vitória, ES, Brasil. E-mail: flapvit@yahoo.com.br

Received January 1, 2011. Accepted October 27, 2011. Available online November 11, 2011. Published January 16, 2012. 
allele with susceptibility to AD. Since the Brazilian population has a high degree of miscegenation, with prevalence of Afro-descendents in the Northeast and of Caucasiandescendents in the South, it is important to determine the role of $A P O E$ gene polymorphisms in the susceptibility to $A D$ in distinct communities. Thus, this study aimed to investigate the influence of $A P O E$ gene polymorphisms among patients with LOAD and non-affected controls in a case-control study on the population from Vitória, ES, a State in the Southeast of Brazil, where the population is primarily composed of Caucasian's, Afro-descendents and Native Brazilians with higher miscegenation.

\section{Material and Methods}

\section{Volunteers}

A total of 264 non-consanguineous individuals from Vitória, ES, a city of the Southeast of Brazil, were studied during the years 2007 and 2008. Among them, 82 participants were patients with a diagnosis of LOAD and the other 182 individuals were controls paired for gender and age at a ratio of $\sim 1: 2$. All participants were selected from the same community in order not to change the ethnic profile among the groups. The participants were primarily Caucasians (approximately $80 \%$ in both cases and controls) and the remaining were Afro-Brazilians.

The volunteers, patients and controls, were recruited by invitation to participate in this study while awaiting care in two public geriatric units in the city of Vitória, ES, Brazil: the Geriatric Unity of the Hospital Santa Casa de Misericórdia de Vitória (HSCMV) and the Centro de Referência de Atendimento ao Idoso (CRAI). Almost $90 \%$ of the invited subjects or their legal representatives agreed to participate. The participants were diagnosed at the Neurogeriatric Unity of the HSCMV or at the CRAI. All patients fulfilled the clinical criteria for probable AD (22) and had a complete diagnostic evaluation for dementia, including CT scan, standard laboratory tests performed at the time of diagnosis and repeated after 2 years (complete blood count, serum electrolytes, serum glucose, blood urea nitrogen, vitamin B12, folate, thyroid function, and syphilis serology), Mini-Mental State Examination (MMSE) (23), and Clinical Dementia Rating Scale (CDR) (24). All patients received treatment with cholinesterase inhibitors at the time of enrollment in the study. The control sample consisted of volunteers who presented a score $>28$ on the MMSE and who did not have any cognitive deficit or any known relatives with $A D$. The study was approved by the Ethics Committee of Human Research of Escola Superior de Ciências da Santa Casa de Misericórdia de Vitória and written informed consent was obtained from all participants or their representatives if the participant could not give consent.

\section{Polymorphisms of the APOE gene}

DNA was extracted according to the methodology de- scribed by Miller et al. (25) from $5 \mathrm{~mL}$ peripheral blood collected into tubes containing 5\% EDTA. The polymorphisms of the $A P O E$ gene were investigated by $\mathrm{PCR}$ restriction fragment length polymorphism (PCR-RFLP) using the primers described by Hixson and Vernier (26) and the following conditions for amplification: $94^{\circ} \mathrm{C}$ for $5 \mathrm{~min}$ for denaturation, followed by 30 cycles at $94^{\circ} \mathrm{C}$ for $30 \mathrm{~s}, 60^{\circ} \mathrm{C}$ for $30 \mathrm{~s}$, and $72^{\circ} \mathrm{C}$ for $30 \mathrm{~s}$, and an extra extension phase at $72^{\circ} \mathrm{C}$ for 7 min. The PCR products were subjected to digestion with the enzyme Hhal (New England Biolabs, USA) at $37^{\circ} \mathrm{C}$ overnight and visualized on $10 \%$ polyacrylamide gel stained with silver nitrate.

\section{Statistical analysis}

The comparison of allelic and genotypic frequencies between patients and controls was performed by the chisquare test $\left(\mathrm{X}^{2}\right)$ and the Fisher exact test was used to estimate the risk of developing $A D$, with a $95 \%$ confidence interval $(95 \% \mathrm{CI})$, using the GraphPad Instat 3.06 software for Windows (27).

\section{Results}

The assessment was performed on 82 LOAD patients (26 males and 56 females, average age of $82.2 \pm 7.5$ years) and 182 non-demented controls (51 males and 131 females, average age of $78.3 \pm 8.3$ years), with no significant differences in age or gender between the two groups.

Table 1 shows the distribution of each genotype and of the allele frequencies and the relative risk of developing $A D$ for each genotype and allele. The distributions of the allele frequencies in LOAD patients and controls were in

Table 1. Genotypic and allelic distribution of $A P O E$ polymorphisms in subjects from Vitória, ES, Brazil.

\begin{tabular}{cccc}
\hline & $\begin{array}{c}\text { LOAD group } \\
(\mathrm{N}=82)\end{array}$ & $\begin{array}{c}\text { Control group } \\
(\mathrm{N}=182)\end{array}$ & $\begin{array}{c}\text { OR } \\
(95 \% \mathrm{Cl})\end{array}$ \\
\hline $\begin{array}{c}\text { Genotype } \\
\text { e2e2 }\end{array}$ & $1(1 \%)$ & $4(2 \%)$ & $0.55(0.06-4.99)$ \\
e2e3 & $4(5 \%)$ & $12(7 \%)$ & $0.73(0.22-2.32)$ \\
e2e4 & $1(1 \%)$ & $8(4 \%)$ & $0.27(0.03-2.18)$ \\
e3e3 & $30(37 \%)^{*}$ & $112(62 \%)$ & $0.36(0.21-0.61)$ \\
e3e4 & $35(43 \%)^{*}$ & $44(24 \%)$ & $2.33(1.34-4.06)$ \\
e4e4 & $11(13 \%)^{*}$ & $2(1 \%)$ & $13.94(3.14-64.50)$ \\
Allele & & & \\
e2 & $7(4 \%)$ & $28(8 \%)$ & $0.54(0.22-1.25)$ \\
e3 & $99(60 \%)^{*}$ & $280(77 \%)$ & $0.46(0.30-0.67)$ \\
e4 & $58(36 \%)^{*}$ & $56(15 \%)$ & $3.01(1.96-4.61)$ \\
\hline
\end{tabular}

Data are reported as number with percent in parentheses. LOAD = late-onset Alzheimer disease; $\mathrm{OR}=$ odds ratio; $\mathrm{Cl}=$ confidence interval. ${ }^{*} \mathrm{P}<0.004$ compared to control group (Fisher exact test). 
Hardy-Weinberg equilibrium $(P=0.0015)$.

When comparing the APOE genotype frequencies between patients and controls, we observed a significant difference for the genotypes e3e3 $(P=0.0003)$, e3e4 ( $P=$ $0.0038)$, and e4e4 ( $<<0.0001)$. A significantly increased risk of $A D$ was observed in carriers of the $A P O E-e 4$ allele. The odds ratio (OR) for the association of LOAD patients with the genotypes e3e4 and e4e4 were 2.33 (1.34-4.06; $\mathrm{P}=0.0038)$ and 13.94 (3.14-64.50, $\mathrm{P}<0.0001)$, respectively. Interestingly, the e3e3 genotype showed a positive association with $A D$ protection $(\mathrm{OR}=0.36,95 \% \mathrm{Cl}=0.21$ $0.61 ; \mathrm{P}=0.0003)$.

The over-represented allele was e3 (0.60), followed by e4 (0.36) and e2 (0.04), in LOAD patients, and e3 (0.77), e4 (0.15), and e2 (0.08) in the control group. We found a significant difference in the frequencies of the e4 and e3 alleles between the LOAD group and controls $(P<0.0001)$, whereas the $e 2$ allele did not reach statistical significance $(P=0.2020)$.

\section{Discussion}

The frequency of the e4 allele was significantly higher in the LOAD patient group (36\%) than in the control group $(15 \%)$, indicating that this allele acts as a risk factor for $A D$ in the population of Vitória, ES $(\mathrm{OR}=3.01,95 \% \mathrm{Cl}=1.96$ 4.61; $\mathrm{P}<0.0001$ ) as demonstrated for other populations (28). Since this is a dose-dependent risk, individuals with the e $3 e 4$ and $e 4 e 4$ genotypes are 2.3- and 13.94-fold more likely to develop $A D$, respectively. However, the protective factor attributed to the $e 2$ allele was not observed in the sample analyzed, possibly because it is a rare allele in the population studied.

On the other hand, we obtained unusual results for the analysis of the $e 3$ allele, suggesting that carriers of the e 3 allele have a $46 \%$ protection against $A D$ in this population (OR $=0.46,95 \% \mathrm{Cl}=0.30-0.67 ; \mathrm{P}<0.0001)$. This protection is maintained when we compare the frequency of the e3e3 genotype between patients with LOAD and controls $(\mathrm{OR}=0.36,95 \% \mathrm{Cl}=0.21-0.61 ; \mathrm{P}=0.0003)$.

$A$ recent study, using meta-analysis strategy to determine the prevalence of APOE-e4 among AD patients across the global population, suggested that $e 4 e 4$ genotype frequency varies among $A D$ patients in regional patterns similarly to those of the general population (29). Whereas European and North American populations were often used in this meta-analysis, the South American continent was analyzed grouped with other communities, showing that there are few studies related to the genetic aspects of $A D$ in South American. Thus, it is important to improve our knowledge about the genetic aspects of AD through studies of different Brazilian cities. Compared to other studies, our sample size was one of the largest analyzed thus far in Brazil for APOE polymorphisms $(15,17,21,30)$.
The frequency of $A P O E$ polymorphisms is highly heterogeneous throughout the world (31-33). For example, the risk attributable to the 44 allele varies by region and by race and ethnicity (29). European researchers observed a gradient with a higher frequency of the $e 4$ allele in the North European continent, and a low frequency in the South. In contrast, the e3 allele goes in an opposite direction (34). The e3 allele is the most frequent in all human groups (10). High frequencies of the e4 allele (37\%) have also been detected in the African population (35). A high frequency of the e3 allele (51-98\%) has been observed in the Brazilian Indian population, followed by e4 (0-47\%) and e2 (0-4\%) $(14,36)$. Our results of allele and genotype frequencies are in agreement with the aforementioned data, possibly due to the high miscegenation of the Brazilian population, which displays genetic influences from all of these populations $(15,37)$.

A recent study performed on the Tunisian population, also using the PCR-RFLP method, reported high frequencies of the e 4 allele in $A D$ patients, whereas the e 2 allele was under-represented (38), as also observed in the present study. Contrary to other studies $(12,13,39)$, an association of the $e 2$ allele with protection against AD was not observed in the present study, probably due to the low frequency of this polymorphism in the sample. Despite the fact that the e3 allele is considered to be the wild type, in our study this allele was associated with a significant protective factor against $A D$, which was only observed in a study from Sicily, Southern Italy (10).

We found higher frequencies of the $e 3$ allele in the control group than in the LOAD patient group. We believe that this allele represents a protective factor against $A D$ in the population from Vitória, ES. Additionally, we found that subjects of this population who carry the e4 allele have an increased risk of developing the disease. These peculiarities might be explained by the ethnic background, in which the frequencies of other alleles of risk to $A D$ can vary among populations. Moreover, distinct environmental factors like oxidative stress, antioxidant intake and aluminum exposition may contribute to the development of the disease (40). These data may provide a new insight into the research on Alzheimer's disease.

\section{Acknowledgments}

We are grateful to the researchers of the Núcleo de Genética Humana e Molecular, UFES, for technical support. We would also like to thank the Secretary of Health of the State of Espírito Santo for allowing the participation of the patients from CRAI and the patients and controls studied in this research. Research supported by Fundo de Apoio à Ciência e Tecnologia de Vitória - FACITEC, Arcelor-Mittal Brazil and Fundação de Amparo à Pesquisa do Espírito Santo - FAPES. 


\section{References}

1. Kachaturian ZS. Diagnosis of Alzheimer's disease. Arch Neurol 1985; 42: 97-105.

2. Storandt M, Grant EA, Miller JP, Morris JC. Rates of progression in mild cognitive impairment and early Alzheimer's disease. Neurology 2002; 59: 1034-1041.

3. Hui JS, Wilson RS, Bennett DA, Bienias JL, Gilley DW, Evans DA. Rate of cognitive decline and mortality in Alzheimer's disease. Neurology 2003; 61: 1356-1361.

4. Cosentino S, Scarmeas N, Helzner E, Glymour MM, Brandt $\mathrm{J}$, Albert M, et al. APOE epsilon 4 allele predicts faster cognitive decline in mild Alzheimer disease. Neurology 2008; 70: 1842-1849.

5. Harold D, Abraham R, Hollingworth P, Sims R, Gerrish A, Hamshere ML, et al. Genome-wide association study identifies variants at CLU and PICALM associated with Alzheimer's disease. Nat Genet 2009; 41: 1088-1093.

6. Lambert JC, Heath S, Even G, Campion D, Sleegers K, Hiltunen M, et al. Genome-wide association study identifies variants at CLU and CR1 associated with Alzheimer's disease. Nat Genet 2009; 41: 1094-1099.

7. Avramopoulos D. Genetics of Alzheimer's disease: recent advances. Genome Med 2009; 1: 34.

8. Corder EH, Saunders AM, Strittmatter WJ, Schmechel DE, Gaskell PC, Small GW, et al. Gene dose of apolipoprotein E type 4 allele and the risk of Alzheimer's disease in late onset families. Science 1993; 261: 921-923.

9. Yoshizawa T, Yamakawa-Kobayashi K, Komatsuzaki Y, Arinami T, Oguni E, Mizusawa H, et al. Dose-dependent association of apolipoprotein $\mathrm{E}$ allele epsilon 4 with lateonset, sporadic Alzheimer's disease. Ann Neurol 1994; 36: 656-659.

10. Bosco P, Gueant-Rodriguez RM, Anello G, Spada RS, Romano A, Caraci F, et al. Allele epsilon 4 of APOE is a stronger predictor of Alzheimer risk in Sicily than in continental South Italy. Neurosci Lett 2005; 388: 168-172.

11. Roses AD. Apolipoprotein $\mathrm{E}$ alleles as risk factors in Alzheimer's disease. Annu Rev Med 1996; 47: 387-400.

12. Corder EH, Saunders AM, Risch NJ, Strittmatter WJ, Schmechel DE, Gaskell PC Jr, et al. Protective effect of apolipoprotein $E$ type 2 allele for late onset Alzheimer disease. Nat Genet 1994; 7: 180-184.

13. Panza F, Solfrizzi V, Torres F, Mastroianni F, Colacicco AM, Basile AM, et al. Apolipoprotein E in Southern Italy: protective effect of epsilon 2 allele in early- and late-onset sporadic Alzheimer's disease. Neurosci Lett 2000; 292: 79-82.

14. de Andrade FM, Coimbra CE Jr, Santos RV, Goicoechea A, Carnese FR, Salzano FM, et al. High heterogeneity of apolipoprotein $\mathrm{E}$ gene frequencies in South American Indians. Ann Hum Biol 2000; 27: 29-34.

15. Oliveira JR, Lima Filho JL, Shimokomaki CM, Okuma M, Passos-Bueno MR, Zatz M, et al. The use of apolipoprotein E genotype for preclinical detection of risk's group for Alzheimer's disease. Am J Med Genet 1997; 74: 216-217.

16. Nishimura AL, Oliveira JR, Mitne-Neto M, Guindalini $C$, Nitrini R, Bahia VS, et al. Lack of association between the brain-derived neurotrophin factor (C-270T) polymorphism and late-onset Alzheimer's disease (LOAD) in Brazilian patients. J Mol Neurosci 2004; 22: 257-260.

17. Oliveira JR, Nishimura AL, Lemos RR, Zatz M. The genetics of Alzheimer's disease in Brazil: 10 years of analysis in a unique population. J Mol Neurosci 2009; 37: 74-79.

18. Bahia VS, Kok F, Marie SN, Shinjo SO, Caramelli P, Nitrini R. Polymorphisms of APOE and LRP genes in Brazilian individuals with Alzheimer disease. Alzheimer Dis Assoc Disord 2008; 22: 61-65.

19. Souza DR, de Godoy MR, Hotta J, Tajara EH, Brandao AC, Pinheiro JS, et al. Association of apolipoprotein E polymorphism in late-onset Alzheimer's disease and vascular dementia in Brazilians. Braz J Med Biol Res 2003; 36: 919923.

20. de Andrade FM, Larrandaburu M, Callegari-Jacques SM, Gastaldo G, Hutz MH. Association of apolipoprotein E polymorphism with plasma lipids and Alzheimer's disease in a Southern Brazilian population. Braz J Med Biol Res 2000; 33: 529-537.

21. Fernandez LL, Scheibe RM. Is MTHFR polymorphism a risk factor for Alzheimer's disease like APOE? Arq Neuropsiquiatr 2005; 63: 1-6.

22. McKhann G, Drachman D, Folstein M, Katzman R, Price D, Stadlan EM. Clinical diagnosis of Alzheimer's disease: report of the NINCDS-ADRDA Work Group under the auspices of Department of Health and Human Services Task Force on Alzheimer's Disease. Neurology 1984; 34: 939-944.

23. Folstein MF, Folstein SE, McHugh PR. "Mini-mental state". A practical method for grading the cognitive state of patients for the clinician. J Psychiatr Res 1975; 12: 189-198.

24. Morris JC. The Clinical Dementia Rating (CDR): current version and scoring rules. Neurology 1993; 43: 2412-2414.

25. Miller SA, Dykes DD, Polesky HF. A simple salting out procedure for extracting DNA from human nucleated cells. Nucleic Acids Res 1988; 16: 1215.

26. Hixson JE, Vernier DT. Restriction isotyping of human apolipoprotein $\mathrm{E}$ by gene amplification and cleavage with Hhal. J Lipid Res 1990; 31: 545-548.

27. Motulsky HJ. GraphPad InStat. Version 3.06. [Computer program]. California: GraphPad Software, Inc.; 2004.

28. Genin E, Hannequin D, Wallon D, Sleegers K, Hiltunen M, Combarros O, et al. APOE and Alzheimer disease: a major gene with semi-dominant inheritance. Mol Psychiatr 2011; 16: 903-907.

29. Crean S, Ward A, Mercaldi CJ, Collins JM, Cook MN, Baker $\mathrm{NL}$, et al. Apolipoprotein E epsilon4 prevalence in Alzheimer's disease patients varies across global populations: a systematic literature review and meta-analysis. Dement Geriatr Cogn Disord 2011; 31: 20-30.

30. Nishimura AL, Guindalini C, Oliveira JR, Nitrini R, Bahia VS, de Brito-Marques PR, et al. Monoamine oxidase a polymorphism in Brazilian patients: risk factor for late-onset Alzheimer's disease? J Mol Neurosci 2005; 27: 213-217.

31. Hallman DM, Boerwinkle E, Saha N, Sandholzer C, Menzel HJ, Csazar A, et al. The apolipoprotein E polymorphism: a comparison of allele frequencies and effects in nine populations. Am J Hum Genet 1991; 49: 338-349.

32. Gerdes LU, Klausen IC, Sinm I, Faergeman O. Apolipoprotein $\mathrm{E}$ polymorphism in a Danish population compared to findings in 45 other study populations around the world. Genet Epidemiol 1992; 9: 155-167.

33. Bazrgar M, Karimi M, Fathzadeh M, Senemar S, Peiravian F, 
Shojaee A, et al. Apolipoprotein E polymorphism in Southern Iran: E4 allele in the lowest reported amounts. Mol Biol Rep 2008; 35: 495-499.

34. Lucotte G, Loirat F, Hazout S. Pattern of gradient of apolipoprotein $\mathrm{E}$ allele *4 frequencies in western Europe. Hum Biol 1997; 69: 253-262.

35. Sandholzer C, Delport R, Vermaak H, Utermann G. High frequency of the apo epsilon 4 allele in Khoi San from South Africa. Hum Genet 1995; 95: 46-48.

36. Demarchi DA, Salzano FM, Altuna ME, Fiegenbaum M, Hill K, Hurtado AM, et al. APOE polymorphism distribution among Native Americans and related populations. Ann Hum Biol 2005; 32: 351-365.
37. Fuzikawa AK, Peixoto SV, Taufer M, Moriguchi EH, LimaCosta MF. Apolipoprotein E polymorphism distribution in an elderly Brazilian population: the Bambui Health and Aging Study. Braz J Med Biol Res 2007; 40: 1429-1434.

38. Rassas AA, Khiari HM, Fredj SH, Sahnoun S, Batti H, Zakraoui NO, et al. High APOE epsilon 4 allele frequencies associated with Alzheimer disease in a Tunisian population. Neurol Sci 2011; doi: 10.1007/s10072-011-0663-8.

39. West HL, Rebeck GW, Hyman BT. Frequency of the apolipoprotein $\mathrm{E}$ epsilon 2 allele is diminished in sporadic Alzheimer disease. Neurosci Lett 1994; 175: 46-48.

40. Thomas P, Fenech M. A review of genome mutation and Alzheimer's disease. Mutagenesis 2007; 22: 15-33. 